\title{
Effects of rainfall intensity on the sediment concentration in the Loess Plateau, China
}

\author{
LIU Xiaoyan" , "DANG Suzhen², LIU Changming ${ }^{3}$, DONG Guotao² \\ 1. Yellow River Conservancy Commission, Zhengzhou 450003, China; \\ 2. Yellow River Institute of Hydraulic Research, Yellow River Conservancy Commission, Zhengzhou 450003, \\ China; \\ 3. Beijing Normal University, Beijing 100875, China
}

\begin{abstract}
To study the effects of changes in the rainfall intensity on sediment concentrations in the Loess Plateau, the observed rainfall intensities and sediment concentrations from three typical small watersheds were used to analyze the relationship between these parameters. The results showed that the sediment concentration generally increased with the increasing rainfall intensity on slope scale. However, at watershed scale, a significant threshold phenomenon was observed for the effects of the rainfall intensity on the sediment concentration. When the rainfall intensity exceeds the threshold, the flood sediment concentration will no longer increase with the increase in the rainfall intensity. The rainfall intensity threshold increased with increasing vegetation coverage. The rainfall intensity threshold was 10-15 $\mathrm{mm} / \mathrm{h}$ during 1956-1969, reached $20 \mathrm{~mm} / \mathrm{h}$ from 1990 to 1997 and is approximately $40 \mathrm{~mm} / \mathrm{h}$ at present. Due to a rainfall intensity of $10-15 \mathrm{~mm} / \mathrm{h}$ almost happened every year, the vegetation did not change much from the 1950s to 1980s. Sediment yield mainly depends on soil erosion caused by surface flow, but the surface flow speed does not increase indefinitely with the increase in the flow discharge. Thus, the annual maximum sediment concentration of the tributaries in the loess area has been basically stable before the 1990s.
\end{abstract}

Keywords: Loess Plateau; loess hilly region; rainfall intensity; sediment concentration; influence

\section{Introduction}

The sediment concentration $\left(\mathrm{kg} / \mathrm{m}^{3}\right)$, sediment load $(\mathrm{t})$, discharge $\left(\mathrm{m}^{3} / \mathrm{s}\right)$ and flood volume $\left(\mathrm{m}^{3}\right)$ are the main characteristic indexes of floods in the Loess Plateau. The sediment concentration is not only the characteristic index of flooding and the key parameter for calculation of the sediment load but is also a characteristic index of the sediment-yield intensity together with the sediment transport modulus $\left(\mathrm{t} / \mathrm{km}^{2}\right)$; this latter parameter constitutes the characterization index of sediment yield in the basin and has attracted much attention.

Received: 2019-03-22 Accepted: 2019-06-08

Foundation: National Key R\&D Program of China, No.2016YFC0402400; National Natural Science Foundation of China, No.51779099

Author: Liu Xiaoyan (1964-), PhD and Professor of Engineering, specialized in the study of runoff and sediment changes in the Yellow River. E-mail: liuxiaoyan@yrcc.gov.cn

"Corresponding author: Dang Suzhen (1983-), PhD and Senior Engineer, E-mail: dangsz_hky@163.com 
At present, research on the sediment concentration in the Loess Plateau mainly involves three aspects: (i) the formation and transport processes of the hyperconcentrated flow (Wang et al., 1982; Zheng et al., 2011; Zheng et al., 2016; Zhao et al., 2017), the erosivity of the hyperconcentrated flow $(\mathrm{Xu}, 1999 \mathrm{a})$ and the spatial distribution characteristics of the hyperconcentrated flow in the Loess Plateau (Zheng et al., 2011; Zheng et al., 2016; Liao et al., 2010); (ii) the impact of the underlying surface on the sediment concentration, such as the soil particle composition, vegetation coverage, slope length, gully density, drainage area, dams and reservoirs (Xu, 1999b; Xu, 2004; Zheng et al., 2007; Zhang et al., 2012; Liu et al., 2015; Gao et al., 2018); and (iii) the influence of rainfall on the sediment concentration (Zhou and Wang, 1987; Zhang, 1991; Tang, 2004; Liao et al., 2010; Zhang et al., 2012; Nishigaki et al., 2017; Wang et al., 2017; Zhang et al., 2017; Zhang et al., 2018). In terms of the relationship between the rainfall intensity and sediment yield, Zhou et al. proposed the rainfall intensity threshold for sediment yield using an "erosion modulus $\leq 1 \mathrm{t} / \mathrm{km}^{2}$ " as the standard (Zhou and Wang, 1987; Tang, 2004); this threshold is for the amount of sediment yield rather than the sediment concentration.

In terms of the relationship between the rainfall intensity and sediment concentration, previous studies have mostly reported laboratory test results (Fang et al., 2015; Wang et al., 2017; He et al., 2017; Zhang et al., 2018), and few studies have focused on the prototype of the Loess Plateau. Based on analysis of observation data from the runoff plot, Zhang et al. (2012) indicated that a larger rainfall intensity led to a higher sediment yield; additionally, the authors proposed that the reason for the poor correlation between the rainfall intensity and sediment concentration was that the precipitation erosion process was random due to heterogeneity of the underlying surface. According to the relationship between the maximum sediment concentration and the relative rainfall intensity (i.e., the ratio of the maximum 1 day rainfall to the annual rainfall) of the 12 tributaries of the Yellow River, Xu (1999b) indicated that a larger rainfall intensity was associated with a higher sediment concentration. However, whether the maximum annual sediment concentration and relative rainfall intensity occurred in the same year and whether other influencing factors were involved were not explained.

Previous studies have concluded that a larger rainfall intensity led to a higher sediment concentration; however, explaining the phenomenon depicted in Figure 1 is difficult. Before the 1990s, little change occurred in the forest and grass vegetation. Although the interannual variation in annual sediment transport was large, interannual variation of the annual maximum sediment concentration was small in many tributaries (especially those with few dams and reservoirs). In fact, the dispersion coefficient $(\mathrm{Cv})$ of the annual sediment discharge from rivers in the Loess Plateau from 1954 to 1975 generally was between 0.7 and 0.85 , which was much larger than the $\mathrm{Cv}$ value of the annual maximum sediment concentration (0.06-0.23) (Liu, 2016). For a given tributary of loess hilly and gully regions, an extreme sediment concentration phenomenon exists (Wang et al., 1982). In nature, the rainfall intensity in the same area generally varies greatly from year to year. For example, the rainfall intensity in the Tuanshan gully in Zizhou from 1962 to 1969 ranged between 1.9 and 52.3 $\mathrm{mm} / \mathrm{h}$, but the interannual variation of the annual maximum sediment concentration was very small. The phenomenon of a sediment concentration limit exists, indicating that the sediment concentration does not increase indefinitely with an increase in the rainfall inten- 
sity. Based on data measured at different spatial scales, this paper focuses on analysis of the influencing mechanism of the rainfall intensity on the flood sediment concentrations in the Loess Plateau.
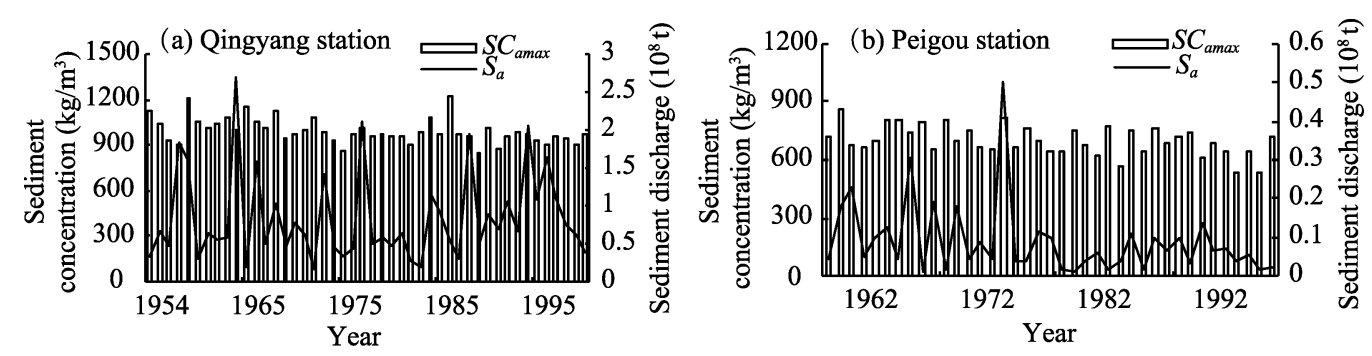

Figure 1 Changes in the annual maximum sediment concentration $\left(S C_{a \max }\right)$ and the annual sediment discharge $\left(S_{a}\right)$ of typical tributaries in the Loess Plateau (a. Qingyang station on the Malian River; b. Peigou station on the Quchan River)

\section{Study area and data}

Wuding River is a first-order tributary of the Yellow River. The study area is located in the middle of the Loess Plateau. Table 1 and Figure 2 provide an overview of the selected watersheds and their locations. Jiuyuangou and Peijiamao are the primary tributaries of the Wuding River. Chabagou is the secondary tributary of the Wuding River. Liujiagou and Shejiagou are the primary tributaries of the Chabagou, whereas Tuanshangou is the subbasin of the Shejiagou.

The observed subwatershed data were collected from Tuanshangou, Shuiwanggou, Tuanyuangou and Qiaogou, whereas the small watershed data were collected from Peijiamao, Liujiagou and Shejiagou. The small watershed system is composed of many subwatersheds. The Tuanyuangou and Qiaogou subwatersheds are located in the Jiuyuangou and Peijiamao watersheds, respectively.

On the runoff plot scale, the observation data were obtained from the No. 2-9 runoff plots in the Tuanshangou subwatershed and the Duanchuan 1 and Duanchuan 2 runoff fields in the Shuiwanggou subwatershed (Table 2). The land use types were all farmland, and the observation period was from 1961 to 1969.

The sample floods selected in this paper are all floods recorded during the selected period. The rainfall, runoff and sediment data are from the hydrological data of the Zizhou Runoff Experimental Station in the Yellow River Basin and the Runoff and Sediment Test Data of Soil and Water Conservation in the Middle Reaches of the Yellow River published by the Upper and Middle Yellow River Bureau, Yellow River Conservancy Commission.

Table 1 The characteristic values of the selected watersheds

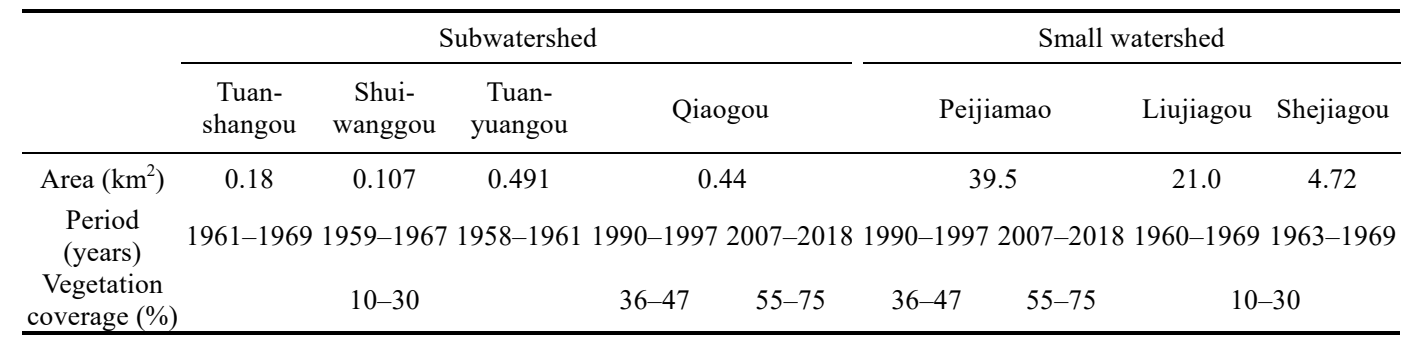




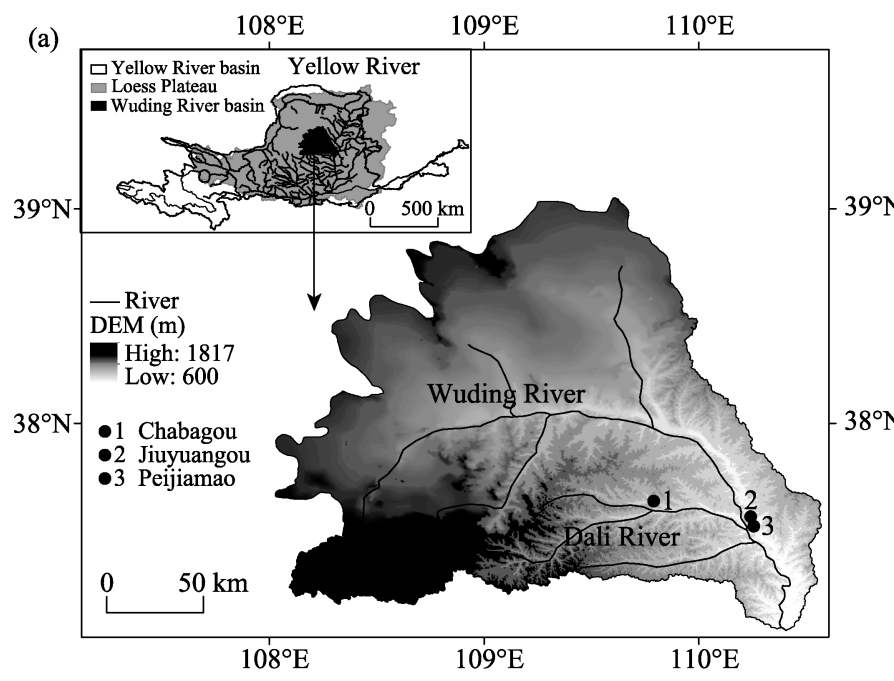

(b)

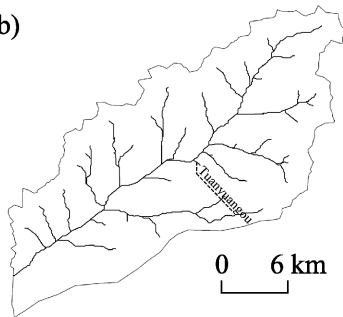

(c)

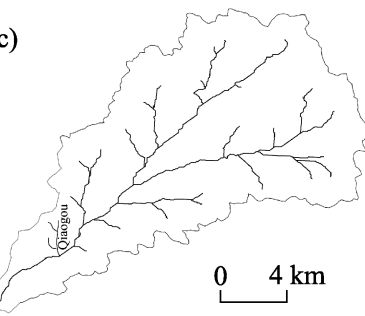

(d)

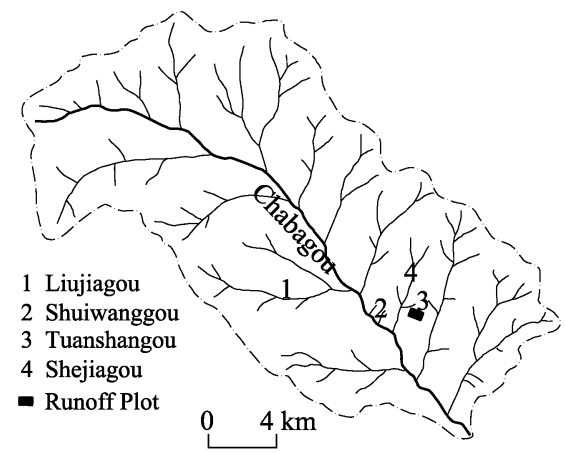

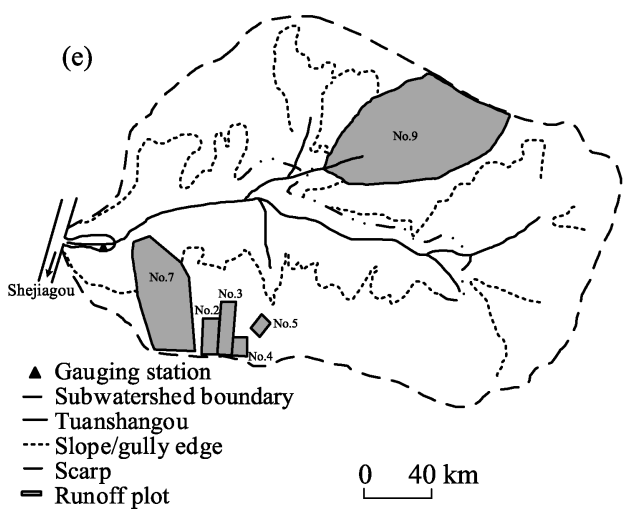

Figure 2 Location of the study area (a. Wuding River basin; b. Jiuyuangou watershed; c. Peijiamao watershed; d. Chabagou watershed; e. runoff plots in the Tuanshangou subwaershed)

Table 2 Overview of the runoff plots

\begin{tabular}{|c|c|c|c|c|c|c|c|c|}
\hline & \multicolumn{6}{|c|}{ Runoff plots located at an upper hillslope } & \multicolumn{2}{|c|}{$\begin{array}{l}\text { Runoff plots composed of hillslope } \\
\text { and valley side slope (entire slope) }\end{array}$} \\
\hline & No. 2 & No. 3 & No. 4 & No. 5 & Duanchuan 1 & Duanchuan 2 & No. 7 & No. 9 \\
\hline Slope length (m) & 40 & 60 & 20 & 20 & 7.57 & 20.1 & & \\
\hline Area $\left(\mathrm{m}^{2}\right)$ & 647 & 970 & 324 & 350 & 31.5 & 208 & 17200 & 4580 \\
\hline
\end{tabular}

Rainfall intensity refers to rainfall in a unit of time in $\mathrm{mm} / \mathrm{min}$ or $\mathrm{mm} / \mathrm{h}$. For the runoff plots and subwatersheds, we selected the maximum rainfall in $1 \mathrm{~min}\left(I_{1 \mathrm{~min}}\right)$ and maximum rainfall in 5 mins $\left(I_{5 \mathrm{~min}}\right)$ before the occurrence of the sand peak as the maximum rainfall intensity $\left(I_{\max }\right)$ of the corresponding sand peak. In the rainfall records for the data collection period, we found that the minimum step size of rainfall was mostly in hours at the small watershed scale, although a few rainfalls were recorded in minutes; however, the step size was uneven. In view of this issue, this paper also chose maximum rainfall in $1 \mathrm{~h}\left(I_{1 \mathrm{~h}}\right)$ as the characteristic index of $I_{\max }$ for small watersheds. The data processing method is as follows: (1) when the rainfall lasted more than $1 \mathrm{~h}$ and the maximum $1 \mathrm{~h}$ rainfall could be obtained 
directly, the maximum $1 \mathrm{~h}$ rainfall before or covering the occurrence of the sand peak was taken as $I_{\max }$ corresponding to the sand peak; (2) when the rainfall duration was less than 45 mins, the flood was not selected to avoid disturbance of the sediment concentration caused by the gully bed during flood evolution; and (3) if the rainfall duration was more than 45 mins but less than $1 \mathrm{~h}$, the measured rainfall intensity was magnified in proportion, and the hourly rainfall intensity was calculated as $I_{\max }$.

For subwatersheds with a drainage area of less than $0.5 \mathrm{~km}^{2}$ and 6-8 rainfall stations, $I_{\max }$ is the average of the maximum $1 \mathrm{~h}$ rainfall of each rainfall station in the subwatershed. By analyzing the measured data from the Chabagou watershed from 1959 to 1969, we found that the sediment concentration of a medium hyperconcentrated flood in any subwatershed with no dam or reservoir to intercept sand could almost completely represent the sediment concentration in the small watershed outlet. In view of this finding, $I_{\max }$ is the maximum value of the maximum $1 \mathrm{~h}$ rainfall of each rainfall station for small watersheds.

Using the Global Inventory Modeling and Mapping Studies (GIMMS) NDVI dataset (NDVI3g, v1.0), the Normalized Difference Vegetation Index (NDVI) of Peijiamao and Qiaogou from 1990-1997 and 2007-2018 was extracted to obtain vegetation coverage information.

\section{The relationship between the sediment concentration and rainfall inten- sity on the plot scale}

Figure 3 shows the relationship between $I_{\max }$ and the peak sediment concentration (PSC) on the upper hillslope scale, with a total of 207 points. Although the slope area and the slope length of each plot are quite different, the PSC of each flood tends to increase with the increasing rainfall intensity. Although the points in Figure 3 are somewhat scattered, the

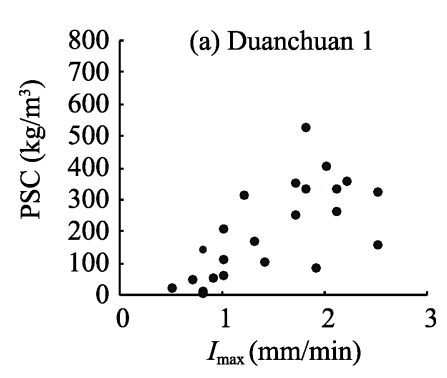

(d) Plot no.5

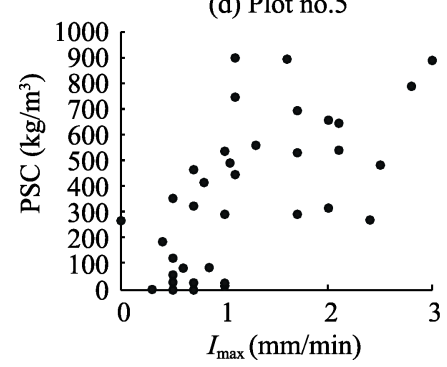

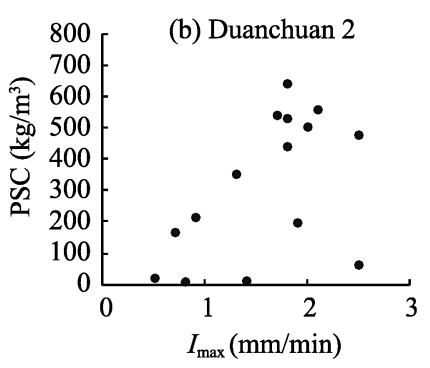

(e) Plot no.2

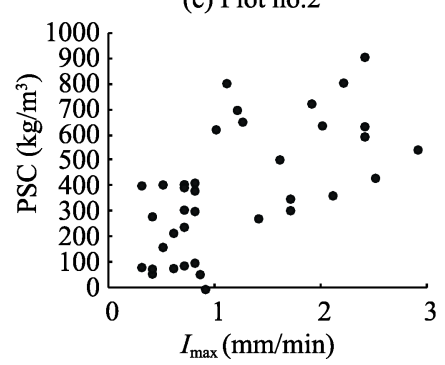

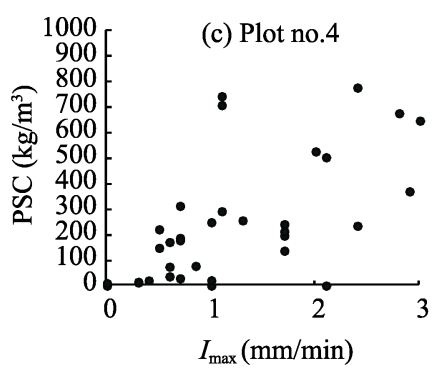

(f) Plot no.3

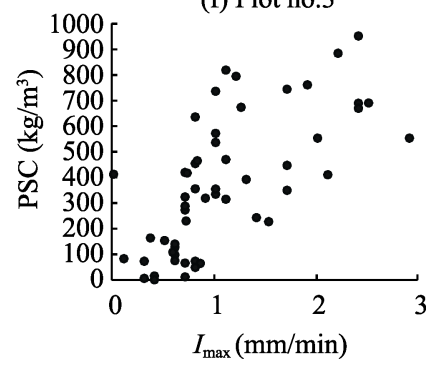

Figure 3 The relationships between the maximum rainfall intensity $\left(I_{\max }\right)$ and the peak sediment concentration $(P S C)$ of the runoff plots located at the upper hillslope 
conclusion is generally consistent with the previous understanding obtained from smaller runoff plots (Zhou and Wang, 1987; Zhang, 1991; Tang, 2004; Zhang et al., 2012; Wang et al., 2017; Zhang et al., 2017; Zhang et al., 2018).

However, the relationship between $P S C$ and $I_{\max }$ shown in Figure 4 for the runoff plots comprised of hillslope, valley side slope (a steep slope area below the edge line) and natural slope gully plots where the hillslope area and the valley side slope area generally are balanced is quite different from that in Figure 3. An obvious threshold phenomenon exists, because in the rainfall intensity range of less than $0.8-1 \mathrm{~mm} / \mathrm{min}$ or $2.5 \mathrm{~mm} / 5 \mathrm{~min}$, the sediment concentration increases rapidly with the increase in the rainfall intensity; however, when the rainfall intensity is larger than this threshold, the sediment concentration is almost independent of the rainfall intensity and generally is stable within a certain range. The same trend holds true if the indicator of $I_{\max }$ is changed to the maximum $1 \mathrm{~h}$ rainfall and the rainfall intensity threshold is $11-15 \mathrm{~mm} / \mathrm{h}$.

(a) Plot no. 9

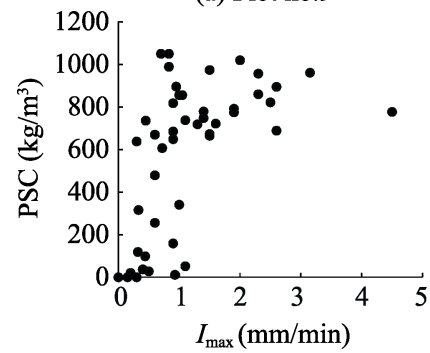

(d) Plot no.7

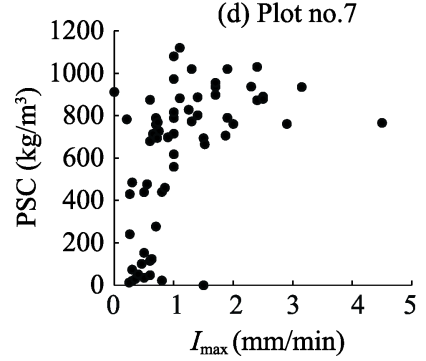

(b) Plot no.9

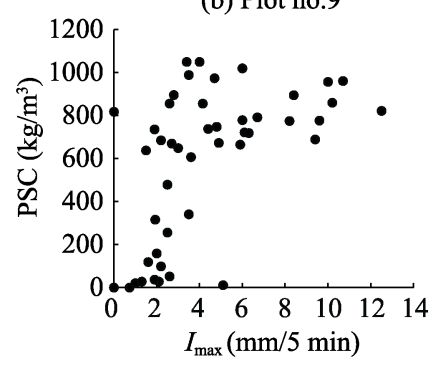

(e) Plot no.7

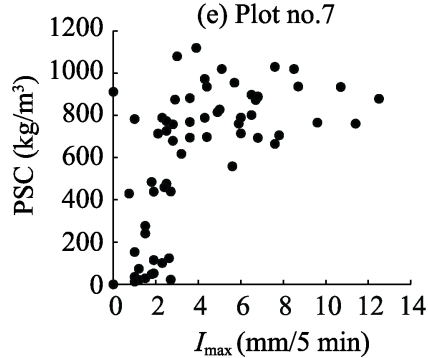

(c) Plot no.9

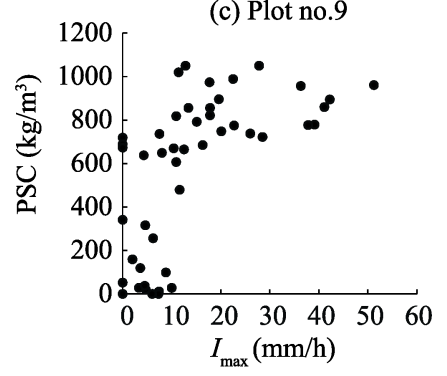

(f) Plot no.7

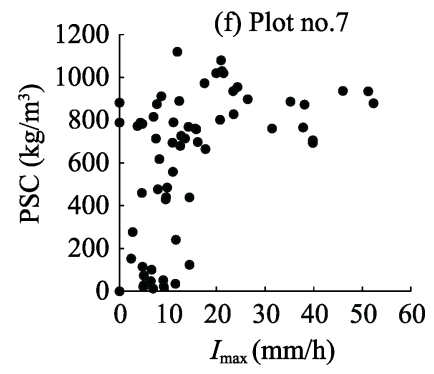

Figure 4 The relationships between $I_{\max }$ and $P S C$ at natural slope gully plots

\section{The relationship between the sediment concentration and rainfall inten- sity on the basin scale}

The natural slope gully plot can be regarded as the lowest level of the drainage area, whereas the subwatershed is a higher level. Figure 5 shows the relationship between the rainfall intensity and sediment concentration in the subwatersheds. The characteristics are similar to those in Figure 4, including the following: (1) the rainfall intensity threshold of Tuanyuangou in the Jiuyuangou watershed is approximately $10-15 \mathrm{~mm} / \mathrm{h}$, and when the rainfall intensity is larger than this threshold, the increasing rainfall intensity has little effect on the sediment concentration; and (2) for the two adjacent subwatersheds in the Chabagou watershed, the rainfall intensity thresholds of Tuanshangou and Shuiwanggou are similar at $1 \mathrm{~mm} / \mathrm{min}$, $4.5 \mathrm{~mm} / 5 \mathrm{~min}$ or $15 \mathrm{~mm} / \mathrm{h}$. Compared with the results of the runoff plots, the rainfall intensity threshold of the Tuanshangou subwatershed is obviously larger than that of the No. 7 
and No. 9 plots during the same period (both runoff plots are located in the Tuanshangou subwatershed).

The vegetation of the Qiaogou subwatershed in the 1990s was much better than that before the $1960 \mathrm{~s}$, and the rainfall intensity threshold was $17-20 \mathrm{~mm} / \mathrm{h}$, which was obviously larger than that of Tuanyuangou, which is adjacent to Qiaogou, in 1956-1961; when the rainfall intensity is larger than this threshold, the PSC is also significantly lower than that of Tuanshangou. After 2007, the annual precipitation with daily rainfall greater than $25 \mathrm{~mm}$ was $30 \%$ higher than that in the 1990s at the Qiaogou subwatershed. However, due to further improvement of the vegetation, the frequency of rainfall that caused runoff decreased from an average of 6-7 times per year in the 1990s to less than once per year after 2007, the maximum sediment concentration was reduced by approximately $50 \%$ and the rainfall intensity threshold probably exceeded $40 \mathrm{~mm} / \mathrm{h}$. However, more verification is needed in the future.
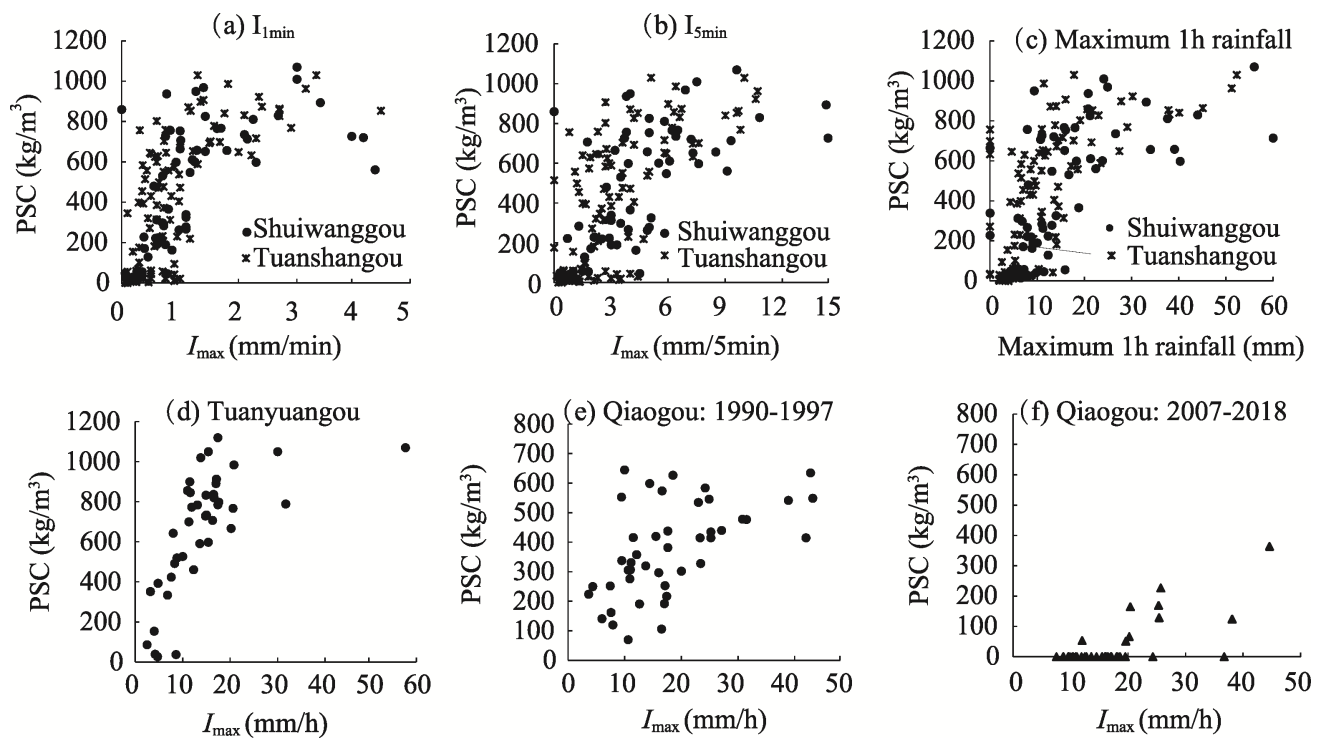

Figure 5 The relationships between $I_{\max }$ and PSC in the subwatersheds

On the small watershed scale with a larger area, as shown in Figure 6, the relationship between $I_{\max }$ and PSC is similar to that shown in Figures 4 and 5. The Shejiagou and Peijiamao small watersheds are the upper levels of the Tuanshangou and Qiaogou subwatersheds, respectively, and Liujiagou is adjacent to Shejiagou. Figure 6 shows that the rainfall intensity threshold of the Peijiamao small watershed is slightly larger than that of the Qiaogou subwatershed during the same period, which is related not only to the size of the drainage area but also to the sediment retention effect of the check dam. In the 1990s, the control area of the check dams in the Peijiamao small watershed accounted for $30 \%$ of the basin area, whereas no check dam was located in the Qiaogou subwatershed.

The rainfall intensity thresholds obtained from the Tuanguangou, Tuanshangou and Shuiwanggou subwatersheds in the 1950s and 1960s were also similar to the standard of erosive rainstorms proposed by others (Zhou and Wang, 1987; Tang, 2004). This finding indicated that once the soil experienced obvious erosion, the extreme value of the sediment concentration would be reached soon. 

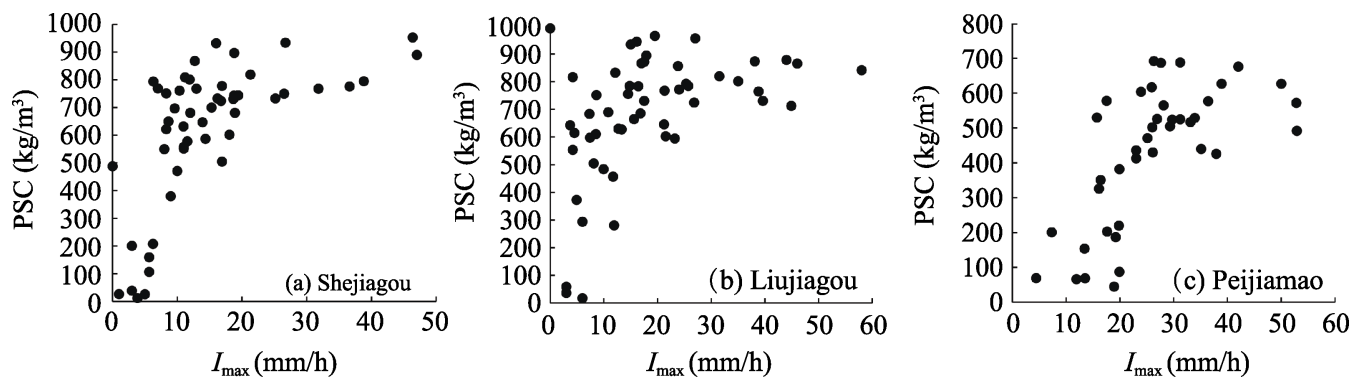

Figure 6 The relationships between $I_{\max }$ and PSC in small watersheds

Rainfall during flood season on the Loess Plateau is mostly local rainstorms with a small coverage area. Therefore, for large- and medium-sized river basins, the corresponding relationship between the rainfall intensity and sediment concentration will be disturbed due to the low density of rainfall stations coupled with the influence of the water flow propagation time and riverbed environment on evolution of the flow with sediment. However, according to analysis of the upper reaches of the Malian River (Zhang et al., 2017), the relationship between the maximum rainfall intensity and the peak sediment concentration basically is consistent with the above results.

\section{Discussion}

\subsection{Comparisons with similar studies}

Phenomena similar to those shown in Figures 3-6 have been found in other studies. Wang et al. discovered the existence of an extreme sediment concentration in the hyperconcentrated flow of the Loess Plateau (Wang et al., 1982). Based on observation data from the whole slope runoff plot (bare area) in Ansai, Zhang et al. (1991) found that when the rainfall intensity was less than $0.8-1 \mathrm{~mm} / \mathrm{min}$, the sediment concentration increased with the increasing rainfall intensity, however, when the rainfall intensity increased, the variation in the sediment concentration on the slope was very small. Zhang et al. (2017) analyzed flood and rainfall data from the Hongde hydrological station on the upper reaches of the Malian River and showed that the $P S C$ was linearly proportional to $I_{\max }$ when the rainfall intensity was less than $18 \mathrm{~mm} / \mathrm{h}$, whereas the $P S C$ remained approximately $900 \mathrm{~kg} / \mathrm{m}^{3}$ when the rainfall intensity was larger than $18 \mathrm{~mm} / \mathrm{h}$. However, few studies have analyzed this phenomenon from different spatial scales, such as runoff plots, subwatersheds and small watersheds.

The sediment-carrying capacity of the overland flow has become a research hotspot in recent years (Zhang, 2007; Zhang, 2018). This term refers to the amount of sediment that can be transported by overland flow under specific hydrodynamic conditions and is related to the flow velocity, flow regime, and other factors, such as the surface slope and slope length. Based on existing knowledge, a greater overland flow velocity (i.e., a larger discharge) results in a larger sediment-carrying capacity of the overland flow. If the real-time sediment concentration is less than the sediment-carrying capacity of the corresponding discharge, the surface soil will be stripped and washed away (i.e., the greater the discharge, the larger the sediment concentration). However, the reality is that no close response exists between the peak discharge and sediment concentration of the tributaries in the Loess Pla- 
teau (Figure 7), although the peak discharge is closely related to the rainfall intensity (Figure 8).

Notably, the sediment concentration of a flood will not increase significantly when the rainfall intensity is larger than the rainfall intensity threshold obtained in this paper, since the sediment discharge in the basin is a function of the discharge, sediment concentration and flood duration. However, because the discharge increases with the increasing rainfall intensity (Figure 8), the sediment discharge in the basin will still increase with the increasing rainfall intensity (Figure 9).

\subsection{The influence of the underlying} surface on the rainfall intensity threshold and maximum sediment concentration

Dam and reservoir sediment retention and vegetation coverage are also important factors affecting the sediment concentration of floods (Cerdan et al., 2002; Liu, 2016). Previous research has shown that vegetation in the Loess Plateau has been improving at a fast rate since 1998 (Feng et al., 2016). Before 1979, check dam construction in the Loess Plateau was mainly concentrated in Shaanxi and

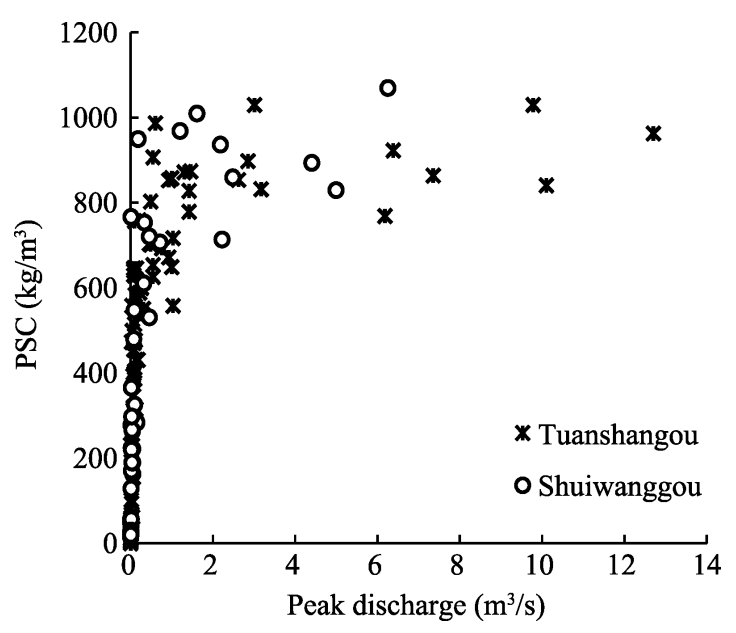

Figure 7 The relationship between the peak discharge and $P S C$ in the subwatersheds

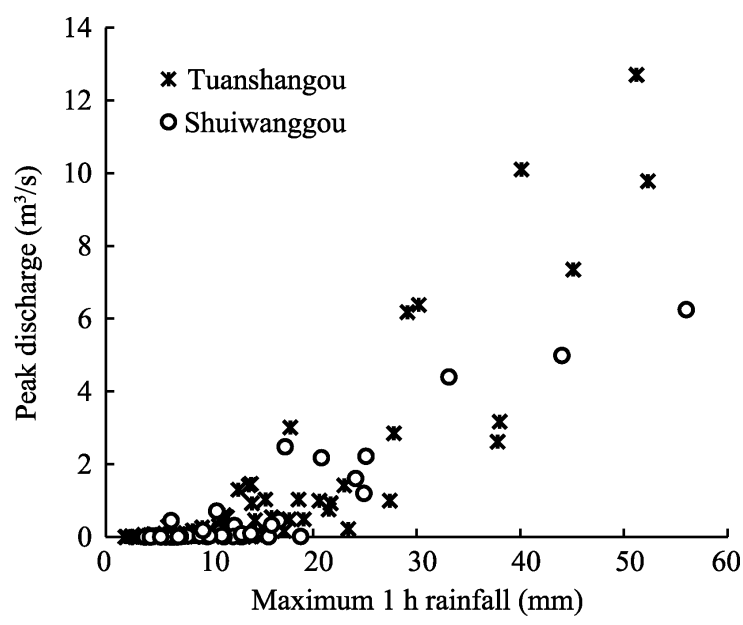

Figure 8 The relationship between the peak discharge and maximum $1 \mathrm{~h}$ rainfall in the subwatersheds Shanxi provinces, and the number of check dams changed little from 1979 to 1997 (Liu et al., 2018). No check dams were present in the Tuanshangou, Shuiwanggou and Tuanyuangou subwatersheds selected in this paper before 1969. Moreover, no check dam is located in Qiaogou at present. Therefore, the influence of check dams on the sediment concentration can be eliminated. The original four check dams in the Shejiagou small watershed were filled up or destroyed by the end of June 1962 (i.e., the check dams had a minimal impact from 1963-1969). Since 1980, the control area of the check dam in the Peijiamao watershed has always accounted for $30 \%$ of the basin area, but $78 \%$ of the check dams have mostly lost their ability to intercept sand at present.

Taking the subwatershed as an example, the average forest and grassland vegetation coverage in the Qiaogou subwatershed from 1990-1997 and 2007-2018 was 36\%-47\% and $55 \%-75 \%$, respectively (Table 1 ). The average maximum annual sediment concentration in the Tuanyuangou, Tuanshangou and Shuiwanggou subwatersheds ranged from $870 \mathrm{~kg} / \mathrm{m}^{3}$ to $1100 \mathrm{~kg} / \mathrm{m}^{3}$. Referring to the ground survey data at that time and the relationship between 


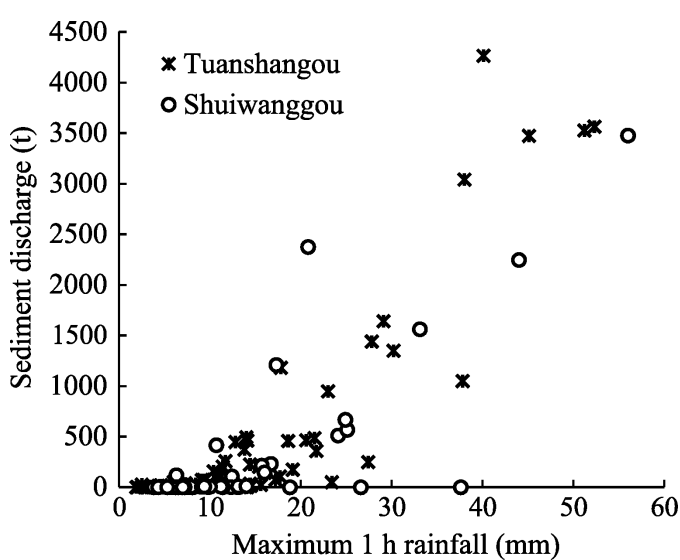

Figure 9 The relationship between the maximum $1 \mathrm{~h}$ rainfall and sediment discharge in the subwatersheds vegetation coverage and the maximum annual sediment concentration (Liu et al., 2015), the forest and grassland vegetation coverage in these subwatersheds during the selected period was estimated to be approximately $10 \%-30 \%$.

The rainfall intensity threshold and maximum sediment concentration of Tuanyuangou from 1956-1961 were 10-15 mm/h and $780 \mathrm{~kg} / \mathrm{m}^{3}$, respectively. In the $1960 \mathrm{~s}$, the rainfall intensity threshold and maximum sediment concentration of Tuanshangou and Shuiwanggou were $15 \mathrm{~mm} / \mathrm{h}$ and $760 \mathrm{~kg} / \mathrm{m}^{3}$, respectively. The rainfall intensity threshold and maximum sediment concentration of Qiaogou in the $1990 \mathrm{~s}$ were $17-20 \mathrm{~mm} / \mathrm{h}$ and 507 $\mathrm{kg} / \mathrm{m}^{3}$, respectively. From 2007 to 2018 , the rainfall intensity threshold of Qiaogou may have exceeded $40 \mathrm{~mm} / \mathrm{h}$, whereas the maximum sediment concentration has not exceeded $400 \mathrm{~kg} / \mathrm{m}^{3}$. No check dams and terraces are located in these areas, and therefore the change in the rainfall intensity threshold is obviously caused by vegetation changes.

For the subwatersheds, during the analysis periods of the different watersheds, the vegetation coverage was highest, the rainfall intensity threshold was largest, and the maximum sediment concentration was smallest at Qiaogou. For the Qiaogou subwatershed, the vegetation coverage in 2007-2018 was higher than that in 1990-1997, the rainfall intensity threshold increased and the maximum sediment concentration decreased.

During the same period, the vegetation coverage of the Peijiamao watershed and Qiaogou subwatershed were the same (Table 1), but the rainfall intensity threshold of the Peijiamao watershed was slightly larger than that of the Qiaogou subwatershed as a result of check dams. Therefore, the rainfall intensity threshold must be different in different watersheds with different underlying surfaces.

\subsection{Causes of extreme sediment concentrations}

The Loess Plateau is the main source of sediment in the Yellow River. The study area of this paper is located in the middle and lower reaches of the Wuding River. According to a remote sensing survey (Liu et al., 2015; Liu, 2016), the middle and lower reaches of the Wuding River were one of the worst vegetation areas in the Loess Plateau before 1998. The vegetation coverage in 1998 was the same as that in other areas of the middle reaches of the Yellow River in the 1970s. The maximum $1 \mathrm{~h}$ rainfall in the Chabagou basin and the loess hilly area of the region from Hekouzhen to Longmen in the middle reaches of the Yellow River Basin was calculated from 1965 to 2011, and the results showed that rainfall with an intensity larger than $15 \mathrm{~mm} / \mathrm{h}$ occurred almost every year on the basin scale (Figure 10). Among the 13,000 maximum $1 \mathrm{~h}$ rainfall data points collected from 1966 to 2017 at the 224 rainfall stations in the region from Hekouzhen to Longmen, the frequency of rainfall with an intensity $\geqslant 10 \mathrm{~mm} / \mathrm{h}$ reached $75 \%$ (Figure 11 ). Therefore, the flooding of each tributary can easily reach its maximum sediment concentration. 
In addition to the frequency characteristics of the rainfall intensity, the unique sediment supply mode may also be the cause of the extreme sediment concentration phenomenon.

Flows with sediment transported in the main stream of the Yellow River and its larger tributaries allocated sediment when entering the river channel. Therefore, there is a feature that "the greater the flow, the more sediment that can be

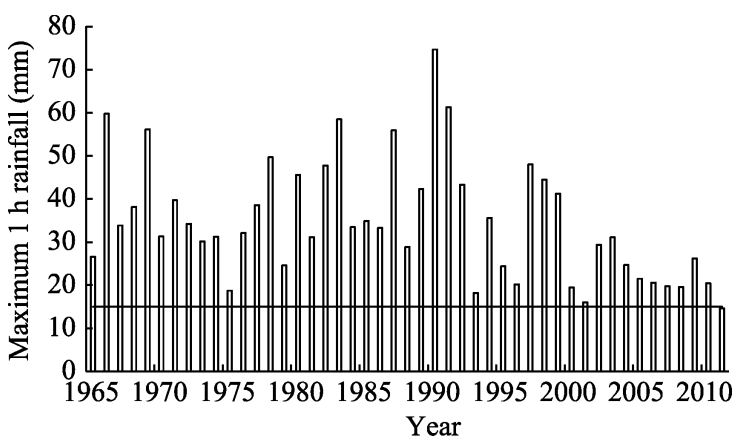

Figure 10 The change of annual maximum $1 \mathrm{~h}$ rainfall in Chabagou Creek

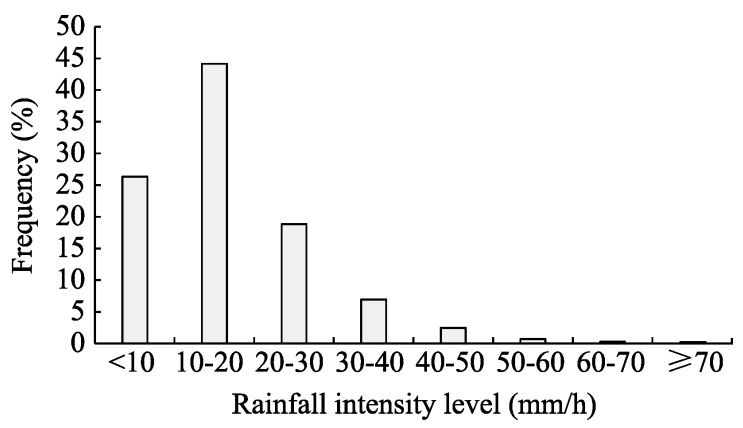

Figure 11 The distribution of the annual maximum rainfall intensity in the loess hilly region from Hekouzhen to Longmen in the middle reaches of the Yellow River Basin area is directly proportional to the velocity of the near-surface flow and inversely proportional to the vegetation coverage of the slope surface. Thus, only the flow attached to the surface can participate in the sediment production activities, whereas other flows can only be engaged in sediment transport activities. The test shows that when the discharge exceeds a certain magnitude, the bottom flow velocity does not increase infinitely with the increase in the discharge. On the other hand, regardless of whether a site is a hillslope or a steep valley slope, increasing the rainfall intensity and the amount of rainfall will inevitably increase the runoff of the slope, because there is no river bank constraint; thus, improving the unit discharge of the slope runoff and the sediment-carrying capacity is difficult even in the absence of blocking vegetation. Therefore, when the rainfall intensity exceeds a certain magnitude, the sediment concentration is basically stable or even reduced, even when the flood discharge continues to increase. After entering the channel, the constraint of the riverbed will increase the unit discharge considerably and greatly increase the sediment-carrying capacity. If a sufficient sediment supply is available at this time, the sediment concentration will increase. However, because the lower riverbeds of the rivers in the Loess Plateau are exposed to bedrock, obtaining a large amount of sediment supply for the water flowing into the river is difficult.

The above analysis shows that forest and grass vegetation changes are not significant at the watershed scale due to rainfall with a rainfall intensity greater than $15 \mathrm{~mm} / \mathrm{h}$, which occurred almost every year from the 1950s to the 1980s (Liu et al., 2015; Zhang et al., 2017). In addition, because the surface flow velocity will not increase indefinitely with the increasing discharge, the annual maximum sediment concentration of the tributaries in the loess 
area before the 1990s was basically stable. Since 2000, the sediment concentration in most tributaries of the Yellow River Basin has decreased significantly with substantial improvement of the forest and grass vegetation in the Loess Plateau.

\section{Conclusions}

The relationship between $I_{\max }$ and $P S C$ at different spatial scales was analyzed based on more than 1300 sets of measured rainfall and flood data from runoff plots located at an upper hillslope, natural slope gully plots, subwatersheds with an area less than $0.5 \mathrm{~km}^{2}$ and small watersheds with an area of $4.7-40 \mathrm{~km}^{2}$ in the Loess Plateau. The results were as follows:

(1) At the upper hillslope scale, the sediment concentration generally increases with the increasing rainfall intensity. However, at the watershed scale with both slopes and gullies, an obvious threshold exists for the influence of rainfall intensity on the sediment concentration regardless of the watershed level or area. When the rainfall intensity exceeds this threshold, an increasing rainfall intensity does not further increase the sediment concentration.

(2) The rainfall intensity threshold is also different in different underlying surface areas. Taking the subwatershed as an example, the rainfall intensity threshold was approximately $10-15 \mathrm{~mm} / \mathrm{h}$ for Tuanyuangou in 1956-1961, $15 \mathrm{~mm} / \mathrm{h}$ for Tuanshangou and Shuiwanggou in the $1960 \mathrm{~s}$, and $17-20 \mathrm{~mm} / \mathrm{h}$ for the Qiaogou subwatershed in the $1990 \mathrm{~s}$ and may have exceeded $40 \mathrm{~mm} / \mathrm{h}$ in 2007-2018. No check dams and terraces are located in these areas, and thus the changes in the rainfall intensity thresholds are obviously caused by vegetation changes. During the same period, the rainfall intensity threshold of the Peijiamao basin was slightly larger than that of the Qiaogou subwatershed as a result of the check dam.

(3) The threshold of the rainfall intensity increases with the increasing watershed level. For example, generally the rainfall intensity threshold of Tuanshangou is larger than that of the No. 7 and No. 9 runoff plots in Tuanshangou. The rainfall intensity threshold of Peijiamao is also larger than that of Qiaogou, because the sediment transport resistance is greater at higher basin levels. As the resistance increases, the sediment concentration also decreases with the increasing basin level. According to statistics from 26 floods in Shejiagou from 1963 to 1969 , the average sediment concentrations were $670 \mathrm{~kg} / \mathrm{m}^{3}$ and $690 \mathrm{~kg} / \mathrm{m}^{3}$ for the No. 7 and No. 9 runoff plots in Tuanshangou, respectively, $634 \mathrm{~kg} / \mathrm{m}^{3}$ for the Tuanshangou subwatershed, and only $585 \mathrm{~kg} / \mathrm{m}^{3}$ for Shejiagou.

(4) When the rainfall intensity exceeds the rainfall intensity threshold, the maximum sediment concentration of each region is also different. The average sediment concentrations were $780 \mathrm{~kg} / \mathrm{m}^{3}$ for Tuanshangou, $760 \mathrm{~kg} / \mathrm{m}^{3}$ for Tuanshangou and Shuiwanggou, and 507 $\mathrm{kg} / \mathrm{m}^{3}$ for Qiaogou in the $1990 \mathrm{~s}$ but never exceeded $400 \mathrm{~kg} / \mathrm{m}^{3}$ after 2007. This phenomenon is mainly related to forest and grass vegetation coverage, with higher vegetation coverage leading to a lower flood sediment concentration.

The rainfall intensity threshold phenomenon that is revealed in this study not only explains the small change in the sediment concentration in the second half of the 20th century but also has important reference significance for the scientific and reasonable selection of rainfall factors in the hydrological method (a method used to analyze the causes of runoff and sediment changes in the basin). Additionally, our results provide scientific support for the objective understanding of the sediment production situation in the Loess Plateau under extreme heavy rainfall. 


\section{References}

Cerdan O, Bissonnais Y L, Souchère V et al., 2002. Sediment concentration in interrill flow: Interactions between soil surface conditions, vegetation and rainfall. Earth Surface Process and Landforms, 27(2): $193-205$.

Fang Haiyan, Sun Liying, Tang Zhenghong, 2015. Effects of rainfall and slope on runoff, soil erosion and rill development: An experimental study using two loess soils. Hydrological Processes, 29(11): 2649-2658.

Feng Xiaoming, Fu Bojie, Piao Sshilong et al., 2016. Revegetation in China's Loess Plateau is approaching sustainable water resource limits. Nature Climate Change, 6: 1019-1022.

Gao Guangyao, Fu Bojie, Zhang Jianjun et al., 2018. Multiscale temporal variability of flow-sediment relationships during the 1950s-2014 in the Loess Plateau, China. Journal of Hydrology, 563: 609-619.

He Jijun, Sun Liying, Gong Huili et al., 2017. Laboratory studies on the influence of rainfall pattern on rill erosion and its runoff and sediment characteristics. Land Degradation \& Development, 28(5): 1615-1625.

Liao Jianhua, Li Danxun, Wang Xingkui et al., 2010. Comparative analysis of spatial distribution between the specific sediment yield and the hyperconcentrated flow frequency in the Loess Plateau. Journal of Natural Resources, 25(1): 100-111. (in Chinese)

Liu Xiaoyan, 2016. Causes of Sharp Decrease in Water and Sediment in Recent Years in the Yellow River. Beijing: Science Press, 11-24. (in Chinese)

Liu Xiaoyan, Gao Yunfei, Ma Sanbao et al., 2018. Sediment reduction of warping dams and its timeliness in the Loess Plateau. Journal of Hydraulic Engineering, 49(2): 145-155. (in Chinese)

Liu Xiaoyan, Yang Shengtian, Li Xiaoyu et al., 2015. The current vegetation restoration effect and its influence mechanism on the sediment and runoff yield in severe erosion area of Yellow River Basin. Scientia Sinica (Technologica), 45: 1052-1059. (in Chinese)

Nishigaki T, Sugihara S, Kilasara M et al., 2017. Surface runoff generation and soil loss under different soil and rainfall properties in the Uluguru Mountains, Tanzania. Land Degradation \& Development, 28(1): $283-293$.

Tang Keli, 2004. Soil and Water Conservation in China. Beijing: Science Press, 41-46. (in Chinese)

Wang Dongdong, Wang Zhanli, Zhang Qingwei et al., 2017. Experiment on influence of cover degree, slope and rainfall intensity on sediment concentration of slope runoff in rangeland. Transactions of the Chinese Society of Agricultural Engineering (Transactions of the CSAE), 33(15): 119-125. (in Chinese)

Wang Xingkui, Qian Ning, Hu Weide, 1982. The formation and process of confluence of the flow with hyperconcentration in the gullied-hilly loess areas of the Yellow River Basin. Journal of Hydraulic Engineering, (7): 28-37. (in Chinese)

$\mathrm{Xu}$ Jiongxin, 1999. Erosion and sediment yield of hyperconcentrated flows on Loess Plateau. Journal of Soil Erosion and Soil and Water Conservation, 5(1): 27-34, 45. (in Chinese)

Xu Jiongxin, 1999. Physico-geographical factors for the formation of hyperconcentrated flows in the Loess Plateau of China. Acta Geographica Sinica, 54(4): 318-326. (in Chinese)

$\mathrm{Xu}$ Jiongxin, 2004. Sediment-heavily containing flows in slope-channel systems of gullied hilly area in the Loess Plateau (I): Influences of landforms and gravitational erosion. Journal of Natural Disasters, 13(1): 55-60. (in Chinese)

Zhang Cuiping, Xu Linjuan, Tian Shimin et al., 2017. Impact of rainfall intensity on flood sediment concentration in Malian River. Yellow River, 39(11): 66-70. (in Chinese)

Zhang Guanghui, 2018. Several understandings for sediment transport capacity by overland flow. Advances in Water Science, 29(2): 151-158. (in Chinese)

Zhang Jianjun, 2007. Summary of studies on sediment carrying capacity of surface runoff on loess slopes. Journal of Sediment Research, (4): 77-80. (in Chinese)

Zhang Keli, 1991. A study on the distribution of erosion and sediment yield on loess slope and the relationship between the distribution and rain characteristics. Journal of Sediment Research, (4): 39-46. (in Chinese)

Zhang Ruibo, Zhang Liping, Fu Xingtao. 2018. Research on the dynamic processes of sediment concentrations in slope runoff with rainfall intensity and slope length. Journal of Soil and Water Conservation, 32(1): 80-84. (in Chinese)

Zhang Xusheng, Xue Tianzhu, Ma Can et al., 2012. Impacts of rainfall intensity and grass coverage on runoff and sediment yield on typical sloping land. Journal of Arid Land Resources and Environment, 26(6): 66-70. (in Chinese)

Zhao Guangju, Yue Xiaoli, Tian Peng et al., 2017. Comparison of the suspended sediment dynamics in two Loess Plateau catchments, China. Land Degradation \& Development, 28: 1398-1411.

Zheng Mingguo, Cai Qiangguo, Chen Hao, 2007. Effect of vegetation on runoff-sediment yield relationship at different spatial scales in hilly areas of the Loess Plateau, North China. Acta Ecologica Sinica, 27(9): 3572-3581.

Zheng Mingguo, Li Ruikun, He Jijun, 2016. Sediment concentrations in run-off varying with spatial scale in an agricultural subwatershed of the Chinese Loess Plateau. Hydrological Processes, 29(26): 5414-5423.

Zheng Mingguo, Qin Fen, Sun Liying et al., 2011. Spatial scale effects on sediment concentration in runoff during flood events for hilly areas of the Loess Plateau, China. Earth Surface Processes \& Landforms, 36(11): 1499-1509.

Zhou Peihua, Wang Zhanli, 1987. Soil erosion storm rainfall standard in the Loess Plateau. Bulletin of Soil and Water Conservation, (1): 38-44. (in Chinese) 